\title{
Aerobic Degradation of Trichloroethylene at High Concentration by a Methane-Utilizing Mixed Culture
}

\author{
Hiroo UchiYama, ${ }^{\dagger}$ Toshiaki NaKaJima, ${ }^{*}$ Osami Yagi \\ and Takeshi TABUCHI \\ The National Institute for Environmental Studies, Water and \\ Soil Environment Division, Tsukuba 305, Japan \\ * Institute of Applied Biochemistry, University of Tsukuba, \\ Tsukuba 305, Japan \\ Received October 20, 1988
}

\begin{abstract}
A number of soil and activated sludge samples were screened as to their ability to degrade trichloroethylene (TCE). A mixed culture involving a soil sample was selected as the most active one. After several subcultures, this mixed culture was found to contain a type II methanotroph, which appeared to be responsible for the TCE degradation. The mixed culture required methane and oxygen for TCE degradation, but methanol, ethanol, ethane, formic acid, acetic acid or glucose could not be substituted for methane. TCE at the high concentration of $10 \mathrm{ppm}$ was degraded to a level corresponding to $\mathbf{4 0} \%$ of the initial concentration in 10 days. The mixed culture was also able to degrade three other chlorinated alkenes, cis- and trans-1,2-dichloroethylene and vinyl chloride, and four chlorinated alkanes, 1,1,2,2-tetrachloroethane, 1,1,2-trichloroethane, 1,2-dichloroethane and chloroform, but not tetrachloroethylene, 1,1,1-trichloroethane or carbon tetrachloride.
\end{abstract}

The Japan Environment Agency ${ }^{1)}$ reported that low-molecular-weight chlorinated aliphatic compounds, such as trichloroethylene (TCE), tetrachloroethylene and chloroform, were detected in more than a quarter of the wells surveyed in Japan, and that 1,1,1-trichloroethane accounted for one-tenth. The U.S. Environmental Protection Agency ${ }^{2)}$ also reported the existence of such groundwater pollution in U.S.A. These occurrences are thought to be linked to the widespread use of these compounds as cleaning solvents in drycleaning operations and semiconductor manufacturing plants or leakage from hazardous waste sites. These compounds are considered to be carcinogens and generally are resistant to biodegradation in the environment. ${ }^{3)}$ Therefore, the Japan Ministry of Health and Welfare set permissible maximum contaminant levels of $10,30,100$ and $300 \mathrm{ppb}$ for tetrachloroethylene, TCE, chloroform and 1,1,1- trichloroethane, respectively, in drinking-water.

Recently, the microbial degradation of these compounds has been studied, especially under anaerobic conditions. $\left.{ }^{4}{ }^{9}\right)$ Vogel and McCarty ${ }^{10)}$ reported that TCE and tetrachloroethylene were degraded under methanogenic conditions. Unfortunately, these anaerobic degradations appeared to result in the formation or the accumulation of dichloroethylene and vinyl chloride, the latter compound being known to be strongly carcinogenic for mammals. $^{11)}$

Under aerobic conditions, chlorinated alkenes have been reported to resist biodegradation. ${ }^{12 \sim 14)}$ But recently, Wilson and Wilson ${ }^{15}$ reported the existence of TCEdegrading soil columns amended with methane and air. Fogel et al. ${ }^{16)}$ reported that a mixed culture containing methanotrophs degraded TCE to carbon dioxide aerobically. Little et al. ${ }^{17)}$ also reported the aerobic TCE degra- 
dation by a type I methanotroph. These degradations were attributed to the metabolic activities of the methanotrophs. Another type of aerobic TCE degradation was described by Nelson et al. ${ }^{18 \sim 20)}$ who reported that a toluene dioxygenase was involved in the TCEdegradative ability of Pseudomonas putida. However, this type of degradation required an aromatic compound, such as phenol, which is also a harmful compound, as an inducer of the enzyme activity. In addition, the aerobically biodegradable TCE concentrations mentioned in these papers were very low (less than $1 \mathrm{ppm})$.

We report here a new type of methaneutilizing mixed culture including a type II methanotroph, which is capable of degrading $10 \mathrm{ppm}$ TCE without an additional energy source to methane. Furthermore, the biodegradative potential of the culture for various volatile chlorinated alkenes and alkanes was examined.

\section{Materials and Methods}

Chemicals. All the volatile chlorinated organic compounds used in this study were of reagent-grade and purchased from Gaskurokogyo Co., Tokyo.

Enrichment of TCE-degrading cultures. Many soil and activated sludge samples collected in various parts of Japan were screened as to their ability to degrade TCE. Soil $(0.2 \mathrm{~g})$ or activated sludge $(5 \mathrm{ml})$ was added to a 155 . $\mathrm{ml}$ serum bottle containing $30 \mathrm{ml}$ of mineral salt medium. The composition of the medium was as follows $(\mathrm{mg} / \mathrm{l})$ : $\mathrm{KH}_{2} \mathrm{PO}_{4}, 450 ; \mathrm{K}_{2} \mathrm{HPO}_{4}, 1170 ; \mathrm{NH}_{4} \mathrm{Cl}, 2140 ; \mathrm{Ca}\left(\mathrm{NO}_{3}\right)_{2}$. $4 \mathrm{H}_{2} \mathrm{O}, 4.8 ; \mathrm{MgSO}_{4} \cdot 7 \mathrm{H}_{2} \mathrm{O}, 121 ; \mathrm{FeSO}_{4} \cdot 7 \mathrm{H}_{2} \mathrm{O}, 28 ; \mathrm{MnSO}_{4}$ $4 \sim 5 \mathrm{H}_{2} \mathrm{O}, 0.6 ; \mathrm{H}_{3} \mathrm{BO}_{3}, 0.05 ; \mathrm{ZnSO}_{4} \cdot 7 \mathrm{H}_{2} \mathrm{O}, 0.1 ; \mathrm{CuSO}_{4}$ $5 \mathrm{H}_{2} \mathrm{O}, 0.06 ; \mathrm{Na}_{2} \mathrm{MoO}_{4} \cdot 2 \mathrm{H}_{2} \mathrm{O}, 0.01 ; \mathrm{Co}\left(\mathrm{NO}_{3}\right)_{2} \cdot 6 \mathrm{H}_{2} \mathrm{O}$ $0.6 ; \mathrm{NiSO}_{4} \cdot 7 \mathrm{H}_{2} \mathrm{O}, 0.06$; and $\mathrm{H}_{2} \mathrm{SeO}_{4}, 0.04$; the final $\mathrm{pH}$ being 7.2. For the solid medium, $1.0 \%$ agarose was added. The serum bottles were sealed with butyl stoppers, which were crimped with aluminum caps. Air $(20 \mathrm{ml})$ was withdrawn from each bottle with a syringe and methane $(20 \mathrm{ml})$ was injected to replace it. TCE $(0.3 \mathrm{ml})$ from a $100 \mathrm{ppm}$ aqueous stock solution was added by means of a syringe through the septa of the bottles, which were then cultured at $30^{\circ} \mathrm{C}$ with shaking at $100 \mathrm{rpm}$. Subculturing was carried out every week, each transfer involving the addition of $1 \mathrm{ml}$ of broth to $30 \mathrm{ml}$ of the fresh medium. The final subculture was stored at $4^{\circ} \mathrm{C}$, without opening of the septum, for use as a stock culture
Analytical methods. TCE degradation was monitored by measuring the TCE concentration in the headspace gas of the serum bottles by gas chromatography. TCE was partitioned between the liquid and gas phases in the serum bottles, and the headspace TCE level was proportional to the liquid concentration. In this paper, accordingly, all the TCE concentration values indicate the liquid concentrations calculated according to Henry's law. The concentrations of the other volatile chlorinated organic compounds examined were also determined by this headspace method.

A gas chromatograph (model GC-7AG; Shimadzu Co., Tokyo) equipped with a ${ }^{63} \mathrm{Ni}$ electron capture detector or a flame ionization detector was used for quantitative determination of volatile organic compounds. The glass column $(0.3 \times 200 \mathrm{~cm})$ was packed with $15 \%$ Silicone DC200 on 60/80-mesh Uniport B (Gaskurokogyo Co., Tokyo). The injector, oven and detector temperatures were 300,120 and $300^{\circ} \mathrm{C}$, respectively. The carrier gas was nitrogen $(50 \mathrm{ml} / \mathrm{min})$. The methane and oxygen concentrations in the headspace gas of the serum bottles were also determined using a gas chromatograph equipped with a glass column $(0.3 \times 200 \mathrm{~cm})$ packed with Molecular Sieve 5A (60/80-mesh; Gaskurokogyo Co., Tokyo) and kept at $80^{\circ} \mathrm{C}$, with nitrogen $(50 \mathrm{ml} / \mathrm{min})$ as the carrier gas. Analytical data were obtained with a computing integrator (model C-R3A; Shimadzu Co., Tokyo).

The absorbance was measured with a spectrophotometer (model DU-64; Beckman, Calif.). Protein was assayed using a protein assay kit (Bio-Rad Lab., Calif.), with bovine plasma albumin as a standard, after whole cells had been preincubated for $45 \mathrm{~min}$ in $1 \mathrm{M} \mathrm{NaOH}$ at $40^{\circ} \mathrm{C}$.

\section{Results}

Characterization of the components of culture $M U-81$

Two-thirds of the 128 samples tested caused a decrease in the TCE concentration on 7 days culture. The most active culture as to degradation, designated as culture MU-81, was subcultured five times as described under Materials and Methods, and used extensively in the present study. In this methane-utilizing culture, the dominant component was a gramnegative, rod-shaped bacterium, with paired membranes along the cell periphery, which was identified as a type II methanotroph. The culture also contained two different bacillus strains and one coccus strain at least. These three strains grew well on nutrient agar, and although they were always observed in any growth phase of the culture, the ratio of total 
cell number of them to that of the methanotroph varied throughout the growth phase, that is, there was a very small number of these bacteria in the middle log phase and about one-tenth in the stationary phase.

\section{Time course of TCE degradation}

Figure 1 shows the time course of TCE degradation by culture MU-81. The stock culture $(50 \mu \mathrm{l})$ was inoculated into $30 \mathrm{ml}$ of fresh medium and then cultured as described under Materials and Methods. TCE (35 ppb) was rapidly degraded during the active phase of cell growth (day 2 to 3), and this TCE degradation was closely related to the con-

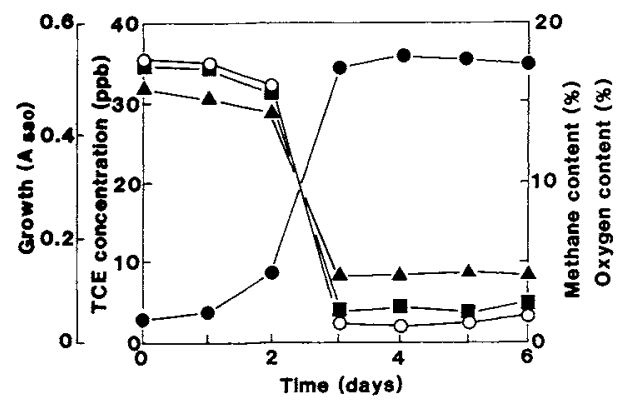

Fig. 1. Time Course of TCE Degradation by Methaneutilizing Culture MU-81.

$\bigcirc$, TCE concentration; $\boldsymbol{\Delta}$, methane content in headspace gas; $\boldsymbol{\square}$, oxygen content in headspace gas; $\boldsymbol{0}$, cell growth.

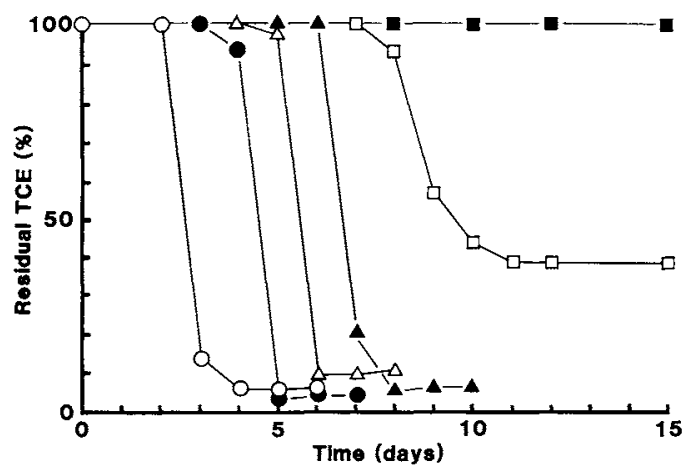

Fig. 2. TCE Degradation at Different Concentrations. The stock culture $(50 \mu \mathrm{l})$ was inoculated into $30 \mathrm{ml}$ of the medium and the experiments were performed in duplicate. The average percent decreases in TCE were compared with those in respective controls, which were not inoculated. The initial TCE concentrations were: $\bigcirc, 35 \mathrm{ppb}$; $0.35 \mathrm{ppm} ; \triangle, 1 \mathrm{ppm} ; \boldsymbol{\Delta}, 3.5 \mathrm{ppm} ; \square, 10 \mathrm{ppm} ; \square, 35 \mathrm{ppm}$. sumption of methane and oxygen. These results indicate that the methanotroph was responsible for the TCE degradation.

\section{Maximum concentration of TCE for deg- radation}

The stock culture $(50 \mu \mathrm{l})$ was inoculated into serum bottles containing TCE at different concentrations, up to $35 \mathrm{ppm}$, and then cultured for 15 days at $30^{\circ} \mathrm{C}$. For the control, the stock culture was not inoculated into serum bottles containing TCE at different concentrations. As shown in Fig. 2, the culture degraded more than $90 \%$ of the TCE, up to a concentration of $3.5 \mathrm{ppm}$, within 8 days. Regardless of the concentration of TCE, the degradation was also related to the cell growth, and the consumption of methane and oxygen. However, at a TCE concentration of $10 \mathrm{ppm}$, the degradation ended at day 11 , due to the total consumption of oxygen in the bottle. The addition of more oxygen further stimulated the TCE degradation (data not shown). In contrast, neither TCE degradation nor cell growth was observed during 15 days in the bottle containing $35 \mathrm{ppm}$ TCE.

\section{Degradation of several chlorinated alkenes and alkanes}

The effect of the culture on the degradation of several chlorinated alkenes and alkanes was examined (Table I). TCE, both cis- and trans1,2-dichloroethylene, 1,1-dichloroethylene, vinyl chloride, 1,2-dichloroethane and chloroform were degraded significantly within about a week. Whereas, 1,1,2,2-tetrachloroethane and 1,1,2-trichloroethane were more resistant to degradation, their amounts decreasing to $24 \%$ and $55 \%$, respectively. The amounts of tetrachloroethylene, 1,1,1-trichloroethane and carbon tetrachloride, however, decreased by only $4 \sim 6 \%$. As these values are within the range of negligible error for the present assay method, it is considered that the latter compounds were not degraded. 1,1-Dichloroethylene at a higher concentration ( $30 \mathrm{ppb}$ ) inhibited cell growth.

No volatile chlorinated intermediates were 
Table I. Degradation of Volatile Chlorinated Hydrocarbons by Culture MU-81

\begin{tabular}{|c|c|c|c|}
\hline Compound & $\begin{array}{l}\text { Initial } \\
\text { conc. } \\
\text { (ppb) }\end{array}$ & $\begin{array}{l}\text { Culture } \\
\text { time } \\
\text { (days) }\end{array}$ & $\begin{array}{c}\text { Decrease }^{a} \\
(\%)\end{array}$ \\
\hline Tetrachloroethylene & 169 & 8 & 4 \\
\hline TCE & 334 & 8 & 95 \\
\hline cis-1,2-Dichloroethylene & 435 & 8 & 93 \\
\hline trans-1,2-Dichloroethylene & 470 & 8 & 98 \\
\hline 1,1-Dichloroethylene & 3 & 8 & 73 \\
\hline Vinyl chloride & 6 & 8 & 100 \\
\hline $1,1,2,2$-Tetrachloroethane & 921 & 7 & 24 \\
\hline 1,1,1-Trichloroethane & 54 & 7 & 6 \\
\hline 1,1,2-Trichloroethane & 87 & 7 & 55 \\
\hline 1,2-Dichloroethane & 83 & 7 & 100 \\
\hline Carbon tetrachloride & 60 & 7 & 5 \\
\hline Chloroform & 16 & 7 & 98 \\
\hline
\end{tabular}

a Data represent average percent decreases compared with those in controls not inoculated with bacteria The experiments were performed in duplicate.

detected on gas chromatography on the degradation of TCE, cis- or trans-1,2-dichloroethylene, 1,1-dichloroethylene, vinyl chloride, 1,1,2,2-tetrachloroethane or chloroform. In contrast, the production of transitory volatile chlorinated intermediates was observed in the cases of 1,1,2-trichloroethane and 1,2 dichloroethane, but none of them corresponded to vinyl chloride.

Effects of carbon sources and anaerobic conditions on TCE degradation

The effect of the addition of carbon sources other than methane on the TCE degradation was examined. Although the culture grew well on methanol, ethanol and glucose, no degradation of TCE was observed (Table II). Ethane, formic acid or acetic acid did not promote cell growth, indicating that the bacterium playing an important role in the TCE degradation was presumably an obligate methanotroph. In addition, TCE was not used as a sole carbon source by the culture, indicating that TCE was degraded through cooxidation associated with the methane metabolism.

When methane was not added to the headspace gas of the serum bottles, neither TCE
Table II. EFFECTS OF CARBON SOURCES ON TCE DEGRADATION

\begin{tabular}{lcccc} 
Carbon & \multicolumn{3}{c}{ TCE (ppb) } & $\begin{array}{c}\text { Growth at } \\
\text { day 7 }(\mu \mathrm{g}\end{array}$ \\
\cline { 2 - 4 } & Initial & Day 4 & Day 7 & $\begin{array}{c}\text { day } \\
\text { protein } / \mathrm{ml})\end{array}$ \\
\hline Methane & 35 & 1.4 & 1.7 & 55 \\
Ethane & 35 & 33 & 32 & 1 \\
Methanol & 35 & 33 & 34 & 204 \\
Ethanol & 35 & 35 & 33 & 336 \\
Formic acid & 35 & 32 & 30 & 3 \\
Acetic acid & 35 & 33 & 32 & 2 \\
Glucose & 35 & 33 & 33 & 177 \\
TCE & 35 & 35 & 34 & 1 \\
\hline
\end{tabular}

a Twenty $\mathrm{ml}$ (methane or ethane), $0.09 \mathrm{ml}$ (methanol, ethanol or formic acid) or $0.3 \mathrm{~g}$ (acetic acid or glucose) of the carbon sources was added to $155-\mathrm{ml}$ serum bottles containing $30 \mathrm{ml}$ of medium.

degradation nor cell growth was observed. Similarly, when all the air in the headspace gas was replaced with nitrogen, neither degradation of TCE nor cell growth was observed, even though methane was present. These results indicate that both methane and oxygen are required for TCE degradation.

\section{Discussion}

The Japan Environment Agency ${ }^{1)}$ reported that 379 out of 1360 wells surveyed were contaminated with TCE, the highest concentration being $4.8 \mathrm{ppm}$. Although the degradation of TCE by aerobic heterotrophic bacteria has been reported, only low concentrations of it were degraded (less than 1 ppm). ${ }^{15 \sim 20)}$ The present culture was able to degrade $10 \mathrm{ppm}$ TCE to a level corresponding to $40 \%$ of the initial concentration in 10 days (Fig. 2) and this period was shortened by increasing the inoculum amount of the stock culture. Accordingly, it appears that the culture may be suitable for environmental remediation.

Although the current TCE-degrading culture, MU-81, contained at least four types of bacteria, the results obtained in this study (Fig. 1 and Table II) strongly indicate that a methanotroph was responsible for the TCE 


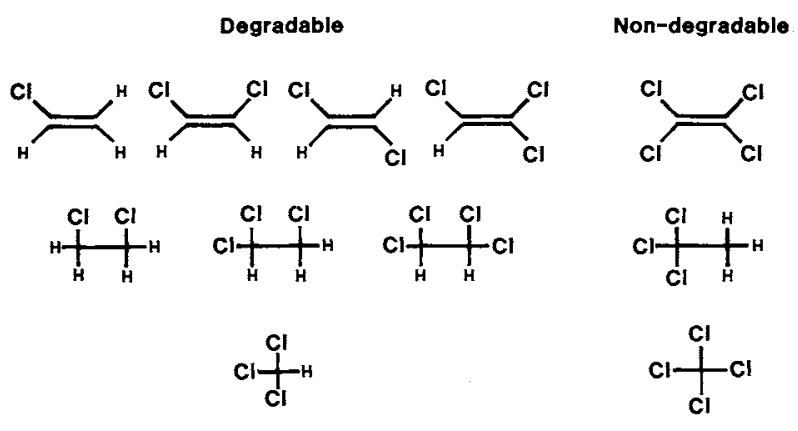

Fig. 3. Chemical Structures Associated with Degradation.

degradation, as previously reported by other researchers. ${ }^{15 \sim 17)}$ It is well known that methanotrophs possess methane monooxygenase, a highly nonspecific enzyme, which is able to insert an oxygen atom into a wide variety of nongrowth compounds. ${ }^{21,22)}$ On such oxygenation, $n$-alkenes change into their epoxides intermediates, followed by conversion to lower-molecular-weight compounds, owing to the instability of the epoxides. ${ }^{22)}$ Miller and Guengerich ${ }^{23)}$ reported that TCE was metabolized by rat liver cytochrome P-450 and the resultant TCE epoxide was broken down spontaneously in phosphate buffer, $\mathrm{pH}$ 7.7 , into glyoxylic, dichloroacetic and formic acids, and carbon monoxide. The heterotrophic bacteria contained in mixed culture MU-81 probably metabolized these products.

The TCE concentrations degraded by other methanotrophs are low (less than $1 \mathrm{ppm}$ ), as described above. To our knowledge, culture MU-81 is the only methane-utilizing culture capable of degrading TCE at a relatively high concentration (10 ppm). Recently, Fliermans et al. ${ }^{24)}$ reported the existence of heterotrophic enrichment cultures which are able to degrade TCE at high concentrations $(68 \sim 76 \mathrm{ppm}$, as estimated by the present assay method). As the TCE degradation was found to begin after cell growth had ended and the cultures were unable to use methane as a sole carbon source, it appears that methanotrophs were not present in these cultures.

Vogel and McCarty ${ }^{10)}$ showed that TCE was biodegraded and that vinyl chloride accumulated as another toxic and undesirable product under anaerobic conditions. In contrast, the present aerobic degradation of TCE by a culture containing a methanotroph was rapid and was not associated with the production of intermediates in the headspace gas of the serum bottles, as judged on gas chromatography.

The possibility of degradation of chlorinated compounds (Table I) by the culture seemed to be closely related to their chemical structures. As shown in Fig. 3, the incompletely chlorinated alkenes could all be degraded, unlike the completely chlorinated alkene, tetrachloroethylene. Similarly, 1,1,1-trichloroethane or carbon tetrachloride, in which one carbon atom at least was completely chlorinated, could not be degraded. This pattern may enable one to predict whether or not other chlorinated compounds can be degraded by the culture.

Nelson et $a l^{20)}$ reported that the natural microflora in several water samples was able to degrade TCE when stimulated by the addition of toluene or phenol. Similarly, methanotrophs are considered to be distributed widely on earth and seem to be latent under natural conditions. However, under certain conditions, including the presence of methane and oxygen, their ability to degrade TCE is induced and activated. These results suggest that bacteria occurring naturally may have the potential to degrade TCE, and that the enzyme related to TCE degradation may become active when stimulated or induced by proper agents. 


\section{References}

1) T. Kawasaki, Jpn. J. Water Pollut. Res., 8, 264 (1985).

2) U. S. Environmental Protection Agency, Fed. Regist., 47, 9349 (1982).

3) P. F. Infante and T. A. Tsongas, Environ. Sci. Res., 25, 301 (1982).

4) E. J. Bouwer, B. E. Rittman and P. L. McCarty, Environ. Sci. Technol., 15, 596 (1981).

5) E. J. Bouwer and P. L. McCarty, Appl. Environ. Microbiol., 45, 1286 (1983).

6) J. M. Suflita, J. A. Robinson and J. M. Tiedje, Appl. Environ. Microbiol., 45, 1466 (1983).

7) F. Parsons, P. R. Wood and J. DeMarco, J. Am. Water Works Assoc., 76, 56 (1984).

8) R. D. Kleopfer, D. M. Easley, B. B. Haas, Jr., T. G. Deihl, D. E. Jackson and C. J. Wurrey, Environ. Sci. Technol., 19, 277 (1985).

9) B. Z. Fathepure, J. P. Nengu and S. A. Boyd, Appl. Environ. Microbiol., 53, 2671 (1987).

10) T. M. Vogel and P. L. McCarty, Appl. Environ. Microbiol., 49, 1080 (1985).

11) C. Maltoni and G. Lefemine, Environ. Res., 7, 387 (1974).

12) C. R. Pearson and G. McConnell, Proc. R. Soc. London, Ser. B, 189, 305 (1975),

13) E. J. Bouwer and P. L. McCarty, Environ. Sci.
Technol., 16, 836 (1982).

14) J. T. Wilson, J. F. McNabb, B. H. Wilson and M. J. Noonan, Dev. Ind. Microbiol, 24, 225 (1983).

15) J. T. Wilson and B. H. Wilson, Appl. Environ. Microbiol., 49, 242 (1985).

16) M. M. Fogel, A. R. Taddeo and S. Fogel, Appl. Environ. Microbiol., 51, 720 (1986).

17) D. C. Little, A. V. Palumbo, S. E. Herbes, M. E. Lidstrom, R. L. Tyndall and P. J. Gilmer, Appl. Environ. Microbiol., 54, 951 (1988).

18) M. J. K. Nelson, S. O. Montgomery, E. J. O'Neill and P. H. Pritchard, Appl. Environ. Microbiol., 52, 383 (1986).

19) M. J. K. Nelson, S. O. Montgomery, W. R. Mahaffey and P. H. Pritchard, Appl. Environ. Microbiol., 53, 949 (1987).

20) M. J. K. Nelson, S. O. Montgomery and P. H. Pritchard, Appl. Environ. Microbiol., 54, 604 (1988).

21) E. R. Leadbetter and J. W. Foster, Arch. Microbiol., 30, 91 (1958).

22) H. Daiton and D. I. Stirling, Phil. Trans. R. Soc. London, Ser. B, 297, 481 (1982).

23) R. E. Miller and P. F. Guengerich, Biochemistry, 21, 1090 (1982).

24) C. B. Fliermans, T. J. Phelps, D. Ringelberg, A. T. Mikell and D. C. White, Appl. Environ. Microbiol, 54, 1709 (1988). 